\title{
(Schiff Base)Mn(III)-Catalyzed Oxidation of Benzylic Hydrocarbons Using Iodosobenzene as the Oxidant
}

\author{
Nam Ho Lee," Jong Chul Byun, and Tae-Heon Oh \\ Department of Chemistry and Research Institute for Basic Sciences, Cheju National University, Ara-1, Jeju 690-756, Korea \\ *E-mail:namho@cheju.cheju.ac.kr \\ Received December 1, 2004
}

Key Words : Benzylic oxidation, Mn(Schiff Base) complex, Iodosobenzene

The oxidation of benzylic $\mathrm{C}-\mathrm{H}$ bonds constitutes one of the most fundamental transformations in organic synthesis. ${ }^{1}$ High valent metal oxides such as $\mathrm{CrO}_{3}$ have long been employed as the oxidant in the hydrocarbon oxidation. ${ }^{2}$ However, stoichiometric use of metallic oxidant could cause a problem associated with either an environmental pollution or difficult separation of the metal reagent from the product. Therefore, as an advanced process, catalytic use of metal complexes in combination with organic oxidant has attracted an attention for the activation of hydrocarbons. ${ }^{3}$ Previously we have reported that (salen) $\mathrm{Mn}(\mathrm{III}) \mathrm{Cl}$ complex 1 could be used as a catalyst in the benzylic $\mathrm{C}-\mathrm{H}$ oxidation using $\mathrm{NaOCl}$ or $\mathrm{PhI}=\mathrm{O}$ as an oxidant. ${ }^{4}$ During the process of this study, we were needed to find the more efficient catalyst. Thus, we decided to investigate other (schiff base)Mn(III) complexes for the catalyst. Described here is the result of our observation on this subject.

For the screening of the catalytic activity, we have synthesized several (schiff base)Mn(III) complexes 1-8 according to the literature procedure. ${ }^{5}$

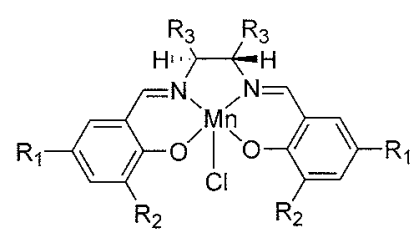

$1 \mathrm{R}_{1}=\mathrm{H} \mathrm{R}_{2}=\mathrm{H} \mathrm{R}_{3}-\mathrm{R}_{3}=-\mathrm{CH}_{2} \mathrm{CH}_{2} \mathrm{CH}_{2} \mathrm{CH}_{2}$

$2 \mathrm{R}_{1}=\mathrm{H} \mathrm{R}_{2}=\mathrm{H} \mathrm{R}=\mathrm{H}$

$3 \mathrm{R}_{1}=\mathrm{Cl} \mathrm{R}_{2}=\mathrm{H} \mathrm{R}_{3}=\mathrm{H}$

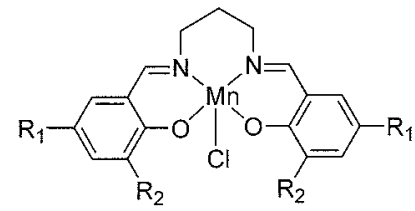

$6 \mathrm{R}_{1}=\mathrm{H} \quad \mathrm{R}_{2}=\mathrm{H}$

$7 \mathrm{R}_{1}=\mathrm{Cl} \quad \mathrm{R}_{2}=\mathrm{H}$

$8 \mathrm{R}_{1}=t-\mathrm{Bu} \mathrm{R}_{2}=t-\mathrm{Bu}$
The catalytic activity of the complexes was examined using ethylbenzene as the model substrate. The result is summarized in Table 1 . The reaction was carried out using 4 mol\% Mn(III) complexes and 3.0 equiv. of iodosobenzene as the oxidant. The reaction was monitored using gas chromatography using 4'-chloroactophenone as the internal standard. ${ }^{6}$ Employment of the (salen)Mn(III) complex 1, the catalyst used in the previous report, ${ }^{4}$ afforded the product (acetophenone) in $39 \%$ yield (53\% conversion). Trial of the other salen-Mn(III) complexes $(\mathbf{2}, \mathbf{3})$ provided slightly lower conversion yields (entries 2,3 ). When the complex $\mathbf{4}$, where 1,2-diaminobenzene-derived ligand was coordinated, was used as the catalyst, slightly higher conversion and product yields waere observed. The complex $\mathbf{5}$, where $\mathrm{Cl}$-substitute was introduced in the ligand, gave no better activity over the complex 4 (entry 5). The complexes 6-8, where 1,3diaminopropane was involved in the ligand, afforded the worse results. From this survey, it was shown the complex 4 has shown the best catalytic activity, even though the difference of the catalytic activity were not high among the complexes 1-5. The reactivity difference between the salen$\mathrm{Mn}$ (III) type complexes could be ascribed to their different electronic and steric properties, which has already been observed in the other type of oxidations. ${ }^{7}$ The other factor worthwhile to mention is the chemical stability of the ligand. In complexes 1-3, they contain $\mathrm{C}_{\mathrm{sp} 3}-\mathrm{H}$ bonds which are considered to be labile under this oxidation. For example, when a simple hydrocarbon such as dodecane was subjected to this reaction conditions, $57 \%$ of starting material was converted to oxidized mixtures based on 4'-chloroacetophenone as the internal standard. On the other hand, the complex 4 does not have $\mathrm{C}_{\mathrm{sp} 3}-\mathrm{H}$ bonds, and therefore is considered to be relatively stable.

With the result in Table 1 at hand, we performed the oxidation with various types of substrates. During the study of this reaction, it was found that the more reliable results were obtained when the reaction was conducted using 8

Table 1. Screening of the (schiff base)Mn(III) complexes for the oxidation catalyst using ethylbenzene

\begin{tabular}{|c|c|c|c|c|c|c|c|}
\hline \multirow{2}{*}{$\begin{array}{l}\mathrm{Ph} \\
\text { Entry }\end{array}$} & \multicolumn{2}{|c|}{+ Cat $(4 \mathrm{~mol} \%$} & \multicolumn{2}{|c|}{$+3.0 \mathrm{Phl}=0$} & \multicolumn{2}{|c|}{$\mathrm{CH}_{3} \mathrm{CN}$} & \multirow{2}{*}{$\begin{array}{l}\mathrm{Ph} \\
\text { Yield }^{a} \\
(\%)\end{array}$} \\
\hline & Catalyst & $\begin{array}{c}\text { Conv. }^{a} \\
(\%)\end{array}$ & $\begin{array}{c}\text { Yield }^{a} \\
(\%)\end{array}$ & Entry & Catalyst & $\begin{array}{c}\text { Conv. }^{a} \\
(\%)\end{array}$ & \\
\hline 1 & 1 & 53 & 39 & 5 & 5 & 41 & 40 \\
\hline 2 & 2 & 45 & 32 & 6 & 6 & 12 & 12 \\
\hline 3 & 3 & 40 & 39 & 7 & 7 & 6 & 6 \\
\hline 4 & 4 & 57 & 44 & 8 & 8 & 6 & 6 \\
\hline
\end{tabular}

${ }^{a}$ Based on GC analysis using 4'-chloroacetophenone as an internal standard. 
mol\% catalyst under ice bath in the presence of molecular sieve as an additive. The results are summarized in Table 2 . When cumene was examined as the substrate, the hydroxylated product, 2-phenyl-2-propanol, as well as methylcleavaged product, acetophenone, was as the major products (entries 1-3). The catalytic activities for complexes 1, 2 and 4 were also compared. As observed in Table 1, the complex 4 proved the better catalyst affording the products in $86 \%$ conversion and $54 \%$ yields. The other unidentified minor products were observed as small impurities based on GC analysis. When sec-butylbenzene was tried as the substrate, similar product pattern was observed (entry 4). Triphenylmethane was also tried as the substrate (entry 5). Triphenylmethanol was obtained in $75 \%$ isolated yield, and small amount of benzophenone was observed as a minor product. In entries 6-10, it has shown that benzylic methylenes were selectively oxidized to the carbonyl compounds. Ethylbenzene and diphenylmethane were

Table 2. Examples of benzylic oxidations using the $\mathrm{Mn}(\mathrm{III})$ complexes as the catalyst

Entry

${ }^{a, b}$ Based on GC analysis using 4'-chloroacetophenone as an internal standard. oxidized to the acetophenone and benzophenone in 65 and $67 \%$ yield (entries 5,6). Tetrahydronaphthalne (in entry 8) was selectively monoxidized to $\alpha$-tetralone in $55 \%$ yield. In entry 9 , isochromanone was selectively oxidized to dihydrocoumarine in $77 \%$ yield. In entry 10 , xanthene was efficiently oxidized to xanthenone in $80 \%$ yield. From this study, it is observed that methylene oxidation to carbonyl is more efficient than the methyne hydroxylation under this reaction condition.

The reaction mechanism for the oxidation of methylene to carbonyl group was tentatively proposed in equation 1 . The oxidation was considered to proceed using $\mathrm{Mn}(\mathrm{V})=\mathrm{O}$ as the active species. (Salen)Mn(III) is well documented to generate $\mathrm{Mn}(\mathrm{V})=\mathrm{O}$ by use of appropriate oxidant such as $\mathrm{NaOCl}$ or $\mathrm{PhI}=\mathrm{O} .{ }^{8}$ The generated $\mathrm{Mn}=\mathrm{O}$ can attack benzylic $\mathrm{C}-\mathrm{H}$ to provide the carbon radical intermediate $\mathbf{9 b}$ and $\mathrm{Mn}(\mathrm{IV})-\mathrm{OH}$, which can undergo recombination (Mn-OH rebound) to afford hydroxylation product 9c. If 9c is a secondary alcohol, it could undergo further oxidation to give the carbonyl compound such as acetophenone $9 \mathrm{~d} .{ }^{9}$ Indeed, as a control study, subjection of the alcohol 9c $(\mathrm{R}=\mathrm{H})$ to the reaction condition led to clean oxidation to give $\mathbf{9 d}$.

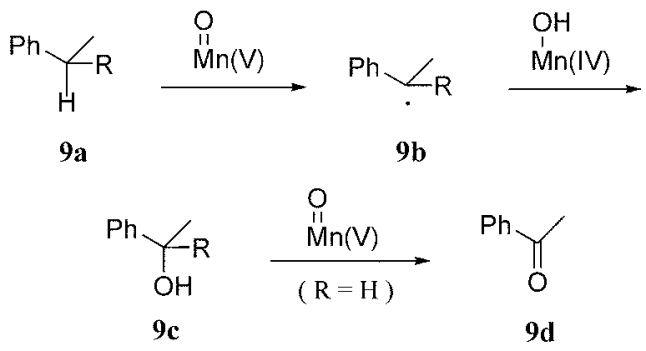

On the other hand, when the oxidation of tertiary alcohol 9c $\left(\mathrm{R}=\mathrm{CH}_{3}\right)$ was conducted under this condition, no reaction was observed. Therefore, the equation 1 is not sufficient to explain the generation of acetophenone from the oxidation of cumene (in entries 1-3 in Table 2). As an alternative procedure, we assume that it is reasonable to propose an alkoxy radical intermediate 9f as a precursor leading to 9d (eq. 2). The alkoxy radical 9f, generated by the disproportion of cumylperoxy radical, has been already proposed as an intermediate in the autoxidation of cumene to provide $9 \mathbf{d} .{ }^{10}$ Accordingly, when we tried the reaction under $\mathrm{N}_{2}$ condition to eliminate the possibility of $\mathrm{O}_{2}$-mediated oxidation, the product ratio of $9 \mathbf{c} / \mathbf{9 d}$ increased slightly to 62/38 (compare to the ratio of 58/42 in Table 2). But, the product yields are almost same under $\mathrm{N}_{2}$ condition. In addition, when the reaction was conducted under $\mathrm{O}_{2}$ condition, a result similar to that shown in entry 3 in Table 2 was obtained. Thus, the involvement of $\mathrm{O}_{2}$ dissolved in the solvent might be only partially responsible for the production of 9d. The other pathway leading to alkoxy radical 9f was tentatively proposed in equation 2. The $\mathrm{Mn}=\mathrm{O}$ species could interact with the carbon radical $\mathbf{9 b}$ to make an intermediate $\mathbf{9 e}$, which eventually can make a homolytic cleavage to afford 9f. When the amount of $\mathrm{PhI}=\mathrm{O}$ was reduced to 1.0 equivalent, the ratio of $9 \mathbf{c}\left(\mathrm{R}=\mathrm{CH}_{3}\right) / \mathbf{9 d}$ increased to $70 / 30$. 
This could be explained by suggesting that the reduced concentration of $\mathrm{Mn}=\mathrm{O}$ species make the pathway leading to 9e less favorable, which resulted in the decrease of $9 \mathbf{f}$ production. However, further studies are still needed to support the proposed this reaction mechanism.

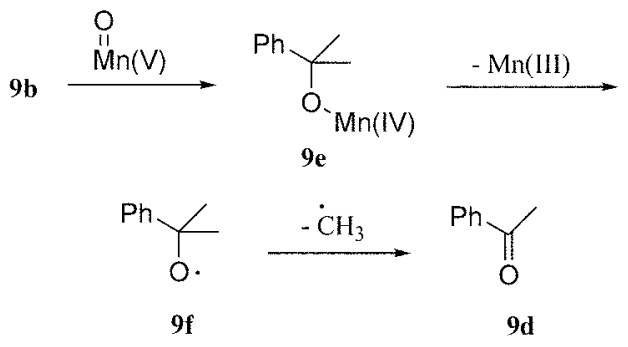

In this paper, by screening of $\mathrm{Mn}(\mathrm{III})$ (Schiff Base) complexes, we have shown that the complex 4 was good catalyst for the benzylic C-H oxidation. The complex $\mathbf{4}$ was found to be easy to handle due to its stability to moisture and air. This process also has mild reaction conditions. Considering the reaction mechanism, the $\mathrm{Mn}=\mathrm{O}$ species are considered as the active oxidation species. Further mechanistic studies to understand the detailed reaction process are still in demand.

\section{Experimental Section}

Iodosobenzene was prepared from the hydrolysis of iodosobenzene diacetate. ${ }^{11}$ (Schiff Base)Mn(III)Cl complexes 1-8 were used after preparation according to the literature procedure. $^{5}$ All of the organic substrates were purchased from Aldrich and used without further purification. The reaction was monitored using gas chromatography (Model: Yonglin M600D) adapted a capillary column (HP-5). The products were identified using GC/MSD (Model: Hewlett Packard HP 5890) or ${ }^{1} \mathrm{H}$ and ${ }^{13} \mathrm{C}$ NMR (Model: Jeol Lambda $400 \mathrm{MHz}$ ) spectrum of the isolated compounds.

General Procedure. To a round-bottomed flask were placed a substrate $(1 \mathrm{mmol})$, the complex $4(33.8 \mathrm{mg}, 0.08$ mmol), molecular sieve $4 \AA$ (800 mg) and solvent $\left(\mathrm{CH}_{3} \mathrm{CN}\right.$,
$10 \mathrm{~mL}$ ). The reaction mixture was stirred for $3 \mathrm{hr}$ under ice bath. After the brine solution $(25 \mathrm{~mL})$ and diethyl ether $(25$ $\mathrm{mL}$ ) were added to the reaction mixture, the organic layer was separated. The small portion of the organic layer was used for GC analysis. The organic fraction was concentrated, and purified by silica gel column chromatography. The products were identified using GC/MSD or NMR spectra by comparison to the authentic reagent.

Acknowledgment. This work was supported by grant No. R05-2004-000-10156-0 from the Korea Science \& Engineering Foundation. This work was also supported by the grant from Academic Research Fund of the Cheju National University Development Foundation (2001).

\section{References}

1. Comprehensive Organic Synthesis (Oxidation); Trost, B. M., Ed.; Pergamon: New York, 1991; Vol 7.

2. Larock, R. C. Comprehensive Organic Transformations: A Guide to Functional Group Preparations; VCH Publishers, Inc.: New York, 1989; pp 591-592.

3. For recent examples, see (a) Das, S.; Bhowmick, T.; Punniyamurthy, T.; Dey, D.; Nath, J.; Chaudhuri, M. K. Tetrahedron Lett. 2003, 44, 4915. (b) Klopstra, M.; Hage, R.; Kellogg, R. M.; Feringa, B. L. Tetrahedron Lett. 2003, 44, 4581.

4. Lee, N. H.; Lee, C.-S.; Jung, D. S. Tetrahedron Lett. 1998, 39, 1385.

5. Byun, J.-C.; Han, C.-H.; Park, Y.-C.; Lee, N. H.; Baik, J. S. J. Korean Chem. Soc. 2002, 46, 194.

6. Screening of various compounds organic compounds revealed that 4'-chloroacetophnone is stable under the reaction condition and suitable as the GC internal standard.

7. (a) Jacobsen, E. N.; Zhang, W.; Gluer, M. L. J. Am. Chem. Soc. 1991, 113, 6703. (b) Lee, N. H.; Byun, J. C.; Baik, J. S.; Han, C.H.; Han, S.-B. Bull. Korean Chem. Soc. 2002, 23, 1363.

8. Posposil, P. J.; Carsten, D. H.; Jacobsen, E. N. Chem. Eur. J. 1996, $2,974$.

9. Lee, N. H.; Baik, J. S.; Han, S.-B. Bull. Korean Chem. Soc. 1998, 19, 726 .

10. (a) Traylor, T. G.; Russell, C. A. J. Am. Chem. Soc. 1965, 87, 3698. (b) Labeque, R.; Marnett, L. J. J. Am. Chem. Soc. 1989, 111, 6621.

11. Saltzman, H.; Sharefkin, J. G. Org. Synthesis, Coll. Vol. 5; 1973; p 658. 